\title{
(6) OPEN ACCESS \\ A Plutocratic Proposal: an ethical way for rich patients to pay for a place on a clinical trial
}

\author{
Alexander Masters, Dominic Nutt
}

Freelance/No affiliation

Correspondence to

Alexander Masters,

alexander.masters@

btopenworld.com

Received 15 November 2016

Revised 2 March 2017

Accepted 29 March 2017

Published Online First

6 June 2017

\section{SLinked}

- http://dx.doi.org/10.1136/ medethics-2017-104251

\section{CrossMark}

To cite: Masters A, Nutt D.

$J$ Med Ethics

2017:43:730-736

\section{ABSTRACT}

Many potential therapeutic agents are discarded before they are tested in humans. These are not quack medications. They are drugs and other interventions that have been developed by responsible scientists in respectable companies or universities and are often backed up by publications in peer-reviewed journals. These possible treatments might ease suffering and prolong the lives of innumerable patients, yet they have been put aside. In this paper, we outline a novel mechanism - the Plutocratic Proposal — to revive such neglected research and fund early phase clinical trials. The central idea of the Proposal is that any patient who rescues a potential therapeutic agent from neglect by funding early phase clinical trials (either entirely or in large part) should be offered a place on the trial.

\section{NEGLECTED DRUGS}

There are many reasons why potential therapies that have shown promise in the preclinical space rarely reach patients. Around $30 \%$ of all drugs fail phase I trials; of those that pass, a further $60 \%$ fail phase II. In the region of $90 \%$ of drugs entering the clinical development process do not complete it. ${ }^{1}$ But many of these failures have nothing to do with safety or efficacy. A study by the Tufts Centre for the Study of Drug Development ${ }^{\mathrm{i}}$ suggests that the leading reason for phase I drug failures is commercial viability; only a third of the drugs the Centre investigated were discontinued on grounds of safety. Just under $30 \%$ of the phase II studies they analysed failed for commercial reasons, rather than efficacy or safety. ${ }^{2}$

CancerCommons, a charity that provides access to therapeutic information for patients with cancer, estimates there are six broadly financial reasons why potentially good treatments get stuck in the translation from preclinical idea to the marketplace: generic drugs (eg, aspirin, metformin) that could be used against new diseases are of no commercial interest to large pharmaceutical companies; effective surgical methods are not promoted because there is no commercial model to drive uptake; natural products cannot secure intellectual patents and so do not interest venture capitalists; novel modes of action always frighten backers, even when preclinical evidence is strong; promising phase II and potential phase III drugs are regularly dropped by biotech companies because of cash constraints-if they have, say, five good candidates to

${ }^{\mathrm{i}}$ The Centre investigated the development histories of 812 compounds and established reasons for failure by clinical phase of 410 . take forward, only one can be chosen; similar thinking leads Big Pharma to drop many potential treatments as part of 'portfolio optimisation' (personal communication from Piers Mahon, Director, Global Alliances at CancerCommons).

For every intervention that is lost in the trials process, uncountable other potential treatments never make it out of the laboratory. Drug developers call the chasm between the large number of promising discoveries made by researchers and the few new potential therapeutic agents that complete early phase clinical trials the 'Valley of Death'. Numerous factors help to create this obstacle: the drug development process with its burden of regulatory paperwork and patent issues alarms basic scientists; promoting innovative ideas into clinical trials can damage a scientist's career because translational research is rarely published by the leading journals; ${ }^{4}$ large pharmaceutical organisations, which once bridged the void between academic and human trials, today focus on drug candidates that have already passed the early regulatory pitfalls; small biotech companies have rushed in to fill the gap, but frequently fail (taking all their good ideas down with them) because of regulatory difficulties, poor funding or inexperienced management. ${ }^{5}$ "There's tons of [neglected] stuff out there", says Dr David Stojdl, senior scientist at the Children's Hospital of Eastern Ontario Research Institute, "and it's dying on the vine". ${ }^{6}$

How many potential interventions remain neglected in this vast preclinical and early clinical space? It is impossible to be precise; it is difficult even to be vague. There is no database for lost basic research; there is not even a way to find out which therapeutic candidates have entered trials, shown promise, but been abandoned all the same, for any one of the many frustrating (to researchers at least) and familiar reasons that have nothing to do with the efficacy or safety of the drug.

There is also the question of repurposing and repositioning. Bernard Munos, a senior fellow at the drug-development advocacy group FasterCures, estimates that around $75 \%$ of all drugs could be tested for repositioning. ' ('Repurposing' and 'repositioning' are still imprecise terms in the literature, often used interchangeably. We take repurposing to refer to finding a new use for an existing medication; repositioning, a new indication for a failed compound.) Paul Workman, head of the Institute for Cancer Research, has said that drugs are available for only $5 \%$ of the 500 known cancer drug targets. "The whole model of cancer drug discovery-in which private companies and academia should be working together to take the most exciting, innovative new drugs to patients—is broken and in need of help." 


\section{THE BACKGROUND}

Four years ago we, AM (a biographer) and DN (a journalist and communications consultant), joined up with Liz Scarff (of Fieldcraft Studios, a social media consultancy) to start a campaign group called iCancer. ${ }^{\text {ii }}$ In 8 months we raised in the region of $£ 2000000$ by a combination of crowdfunding and a novel version of venture philanthropy to fund phase I and phase IIa trials of an advanced biologic for neuroendocrine cancer: AdVince-an oncolytic adenovirus. ${ }^{9} 10$ The campaign had been initiated by one of us (AM) to help a friend who had metastatic pancreatic neuroendocrine cancer.

The preclinical research into the engineered adenovirus had been conducted at Uppsala University, Sweden, and published in respected international journals. ${ }^{11-14}$ To confirm that the new agent deserved to be tested in clinical trials, we asked three leading virotherapists and cancer researchers to review this body of work, and hosted a Skype conference between two of these independent assessors and Professor Magnus Essand, the principal investigator in Uppsala.

Several major factors, each directly or indirectly financial, had prevented the drug from being developed, despite promising preclinical results: there were no suitable European Union grants available for advanced biological clinical research into this rare cancer; the Swedish government had a policy (at the time-since changed) of not supporting clinical trials; Sweden is a small country and no cancer charity that might back this Swedish proposal had sufficient funds; the patent on the drug was weak; finally, the principal investigator had just finished setting up a trial of another oncolytic virus (to treat prostate cancer) and, exhausted by the regulatory process and unable to fund a postdoc to take over this onerous task, wanted to get back to directing research.

We had assumed, during our fundraising, that the neglect at Uppsala was a rare event-a concatenation of unfortunate but unusual circumstances. We discovered that we were wrong. Over the next several years, we heard many reports of other lost potential therapeutic agents, at both preclinical and clinical stages, and investigated three in detail. This small sample provides further evidence of the numerous non-medical reasons why potentially life-saving drugs are dropped, at all points of the drug development process, from basic laboratory research to advanced human trials.

First, in Philadelphia, another promising oncolytic virus, Seneca Valley virus (SVV), had already entered two trials for treating neuroendocrine tumours (a phase I trial, for childhood brain cancer; a phase II trial for small cell lung cancer). The company running the trials, Neotropix, was abandoned by the venture capitalists because the research was progressing too slowly(personal communication from Peter Lanciano, then CEO of Neotropix). From the point of view of the investors wanting to shed some of their portfolio, even had SVV passed early phase trials and been successful, its appeal to Big Pharma might be limited, because neuroendocrine cancer is rare. Although today there are regulatory inducements to make orphan diseases a profitable research topic, in the period during which SVV was being developed (2007-2010) Big Pharma had little interest in rare cancers.

Patient interest was intense. Preclinical and anecdotal reports from the early phase clinical trials were encouraging. Nancy Pelosi, then Speaker of the House of Representatives, attempted

ii The iCancer website is at http://www.iCancer.org.uk. (accessed Mar 2017). to force the company to provide samples for the daughter of a friend of hers who had neuroendocrine cancer, but Neotropix refused on ethical and commercial grounds. The case was discussed in the Wall Street Journal. ${ }^{15}$ Two years later, the funders withdrew and the company went bust.

Second, at the Stojdl Lab, University of Ottawa, a potential candidate for the treatment of glioblastoma multiforme (the most common primary brain cancer tumour in adults) was put aside because funds for basic immunotherapy research in 2008 were difficult to locate under the then conservative Canadian government of Stephen Harper. The researchers subsequently moved on to other products, and the neglected drug has lain in a freezer at Ottawa ever since. Another oncolytic virus (because of our work with Uppsala, it was these drugs we tended to hear most about), it also offered promise as a potential vaccine against Ebola because its manufacture involved introducing an Ebola protein to protect the central nervous system.

Third, in Manchester, a trial of adjuvant chemotherapy for the disease that had provoked us to begin our fundraising for Uppsala: pancreatic neuroendocrine cancer. This phase II trial was less expensive than the Uppsala study, and the drugs were already readily available and tested for safety: but the proposed clinical research could not obtain backing because the disease is very rare; it tends to progress too slowly to be considered a priority by statutory or charitable funders, let alone commercial ones; it would be difficult to recruit patients for the proposed trial, which would take up to 10 years to complete and have endpoints that are hard to characterise. "Two of the leading reasons why companies may leave a disease area abandoned", says Dr Craig Lipset, Head of Innovation at Pfizer, "are when the outcomes are very long to follow, because this creates very expensive trials, and when [the research] has poor endpoints, because these make it extremely challenging for anyone to run a trial” (personal communication).

The urgency of this paper therefore depends on two imprecise but unremarkable assumptions: (1) that there are a considerable number of neglected therapeutic ideas and potential medical interventions in the preclinical and early phase clinical space, and (2) that the problem is caused by a complex of financial and motivational reasons.

We have a radical funding proposal that could help to get neglected therapeutic candidates back into the development process. We call it the Plutocratic Proposal. Here, we will explain a simple version of this idea in detail, explain why we think it could help overcome some of the difficulties that currently prevent new therapeutic agents from reaching patients, and investigate the ethical strengths and potential weaknesses of the idea. Although we argue that the Plutocratic Proposal is at least as ethical as the current, well-established funding mechanisms (and, we believe, in several respects considerably more so), our aim is to present the idea for debate. As far as we know, nothing like the Plutocratic Proposal has been discussed before in the academic literature.

\section{THE PLUTOCRATIC PROPOSAL}

The suggestion of the Plutocratic Proposal is that any donor who rescues a potential therapeutic agent from neglect by funding necessary clinical trials (either entirely or in large part) should be offered a place on the trial. The donor can choose either to participate herself or to award the trial place to any another suitable patient: a friend, relative or stranger.

A simple illustration of the Proposal at work might run as follows: a rich person is diagnosed with neuroendocrine cancer -a rare disease for which there are few bespoke treatments. 
Figure 1 The Plutocratic Proposal. In more sophisticated versions, there could be more than one donor per trial, or more than one trial funded by one or more donors. It is also, we believe, possible to construct an ethically acceptable version that allows donor-patients to receive the drug even if they are no longer suitable for the trial (see Masters A. A Plutocratic Proposal. Mosaic $2014^{6}$ ). The function of the outreach team is to help populate the database of promising neglected interventions.

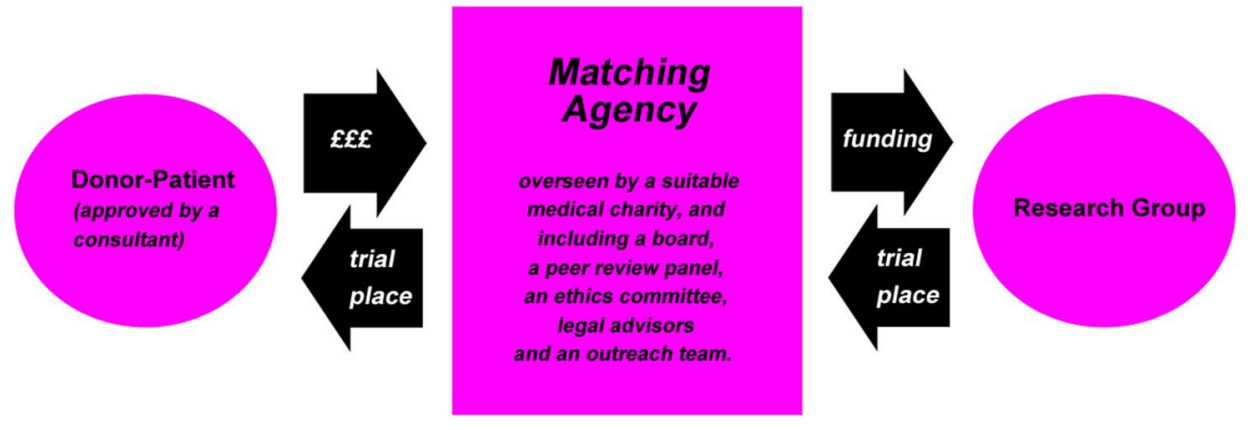

The patient's consultant explains that, in addition to the usual treatments on offer, there are a number of as yet untested, underfunded interventions that stand a small chance of helping her if surgery is ineffective or (if the disease is already metastatic) when the traditional treatments stop working. If the patient was able to pay for a clinical trial of one of these potential therapeutic agents, fully or in large part (ie, pay not just for herself but for all the other patients involved), she would be assured participation in the trial in 2-3 years' time, once all the preparatory work had been completed, the trial approved and the drug ready, and assuming she was still a suitable candidate come the time.

This is a long-term commitment. In general, the Plutocratic Proposal will be suitable only for patients with a life expectancy of at least 3 years. The exact length of time the donor will have to wait for the trial to begin will depend on many factors: the research stage of the neglected intervention, the commitment of the scientists and the speed of the regulatory process. It is possible that the candidate drug will not be approved for a clinical study.

If the rich patient is interested in the suggestion, her consultant refers her to an independent charitable organisation that, for the sake of evocation, we will call the Matching Agency. The job of this agency is to maintain a database of neglected potential therapeutic agents and to match the donor to a suitable intervention that could possibly be investigated in a clinical trial within a sufficiently short space of time.

Should the rich patient decide to go ahead, the Matching Agency then acts as an intermediary between the researchers and the patient. This role includes organising proper review (ie, a systematic investigation of published and unpublished material, to confirm that the researchers' promise is evidence based) and ensuring that the trial process that follows is ethical, scientifically useful and financially secure.

Finally, once the drug has been manufactured to the required standard and is ready for use, the patient will again be independently assessed to ensure she still meets the inclusion criteria. If so, she joins the trial. If not, she does not.

\section{THE PLUTOCRATIC PROPOSAL IS 'COMMITTED PHILANTHROPY'}

The Plutocratic Proposal suggests that we introduce a third motivation for financing early phase clinical research, which lies between the two currently accepted methods of profit (venture capitalists and Big Pharma investment) and altruism (charitable/ statutory donations or venture philanthropy): instead of the donor-patient investing for financial gain, she is doing it in the hope of getting access to a beneficial drug. In other words, the
Plutocratic Proposal picks out a new source of money for translational research by identifying a new motivation to fund early stage clinical drug studies. We believe this will encourage the search for fresh, commercially risky approaches to treating diseases. Donors-patient will have an interest in supporting work that is significantly different to that already available: their donation is made on the assumption that the currently available drugs may eventually fail to treat them. Their investment is motivated by the search for innovation. It is not held back by commercial fears.

We call the new funding mechanism introduced by the Plutocratic Proposal 'committed philanthropy'. iii The ambiguity of the word 'committed' is deliberate: under the Plutocratic Proposal the donor must commit herself, while still in comparative good health and with a good prognosis, to a great financial and scientific risk; if she decides to take it, she is shackled to benevolence.

\section{DISTINCTIVE FEATURES OF THE PLUTOCRATIC PROPOSAL}

Various distinctive features of the Plutocratic Proposal (figure 1) and the role of the Matching Agency need to be stressed.

First, the patient and the researchers do not come into direct contact. This is essential, to protect each side from exploitation and manipulation. The patients are vulnerable; they could be influenced by the researchers' eagerness (even if well meaning) to see a trial go ahead. The researchers are dependent on the donor's money: they could be influenced by the patient's impatience to rush the trial. The Matching Agency acts as defender to both patient and lab. To the donor, it guarantees that the proposed research project is of a good standard and likely to take place within a sufficiently short space of time; to the scientists, that the agreed money will follow without complication or unwarranted interference.

Second, in this simplest version of the Plutocratic Proposal only one patient on the trial has paid for participation. Her money will finance not just all the extra preclinical research still necessary, and all the regulatory paperwork and the manufacture of a sufficient number of trial doses, but it will also pay for all the other patients on the study who would otherwise have no chance to try this untested but potentially useful agent. The Plutocratic Proposal is not a way to reserve promising research for the wealthy or privileged. It opens access to potential new treatments for all.

It is easy to imagine a less strict version of the Plutocratic Proposal, in which two (or more) rich patients are allowed to

iii The authors wish to thank Dr Flora Dennis for suggesting this term. 
pay for the chance to participate in the same future trial. At what point does this balance between donating and ordinary patients become unethical? Julian Savulescu argues that up to half of the participants should be allowed to be donors (personal communication). (Another question is, how large must a donation be, to secure the offer of a place on the trial? In the case of the trial in Uppsala, around $£ 700000$ came from crowdfunding; the remainder, roughly $£ 1.3$ million, from Vince Hamilton's donation.)

Third, the trial place is not guaranteed to the patient, even once the patient's money has been accepted. Ultimate inclusion in the trial must depend on her (or her elected patient) meeting the inclusion criteria when the trial starts. It will be part of the job of the Matching Agency to negotiate appropriate criteria (ie, to strike the optimal balance between the donor's prognosis and the scientific value of the research). Unless the Matching Agency has strong governance, there is certainly room here for ethical misbehaviour. The Agency must ensure both that donors do not undermine the scientific value of a study by their eagerness to have inappropriate criteria (to increase the chances of a future place) and that researchers (in the eagerness for funds) do not promote work that stands little chance of being suitable for the donor once the study begins.

Fourth, the decision to make this donation will usually have to be settled early on in the donor-patient's treatment plan, when there is still hope that the other treatments might be sufficient. This acts as a safeguard to protect the donor from exploitation. There will be no point in the patient giving the money in the desperate days once the traditional therapies have run their course: by then she will not have enough life left.

Fifth, the types of trials suitable for this proposed funding arrangement are restricted to those that do not have formal, concurrent comparators. This is most likely to mean only phase I and phase IIa trials. Although it is possible to imagine how to extend the reach of the Plutocratic Proposal beyond these early phases of clinical experimentation, in the simplest case we are discussing here it would be unethical (as well as scientifically damaging) for our rich patient, for example, to set up and take part in a comparison trial, but only on the condition that she is put on the treatment wing.

Sixth, the donor's money must be paid, in full, in advance. The Matching Agency will then act like a bank, providing tranches of cash to the researchers as they pass certain previously agreed stages in their work to bring the drug into trial. This is to avoid the patient (or her estate) backing out of the exchange if, for example, her indication changes, or if her investments collapse before the trial is complete, and she cannot afford to pay the remainder of the bill, or if she dies. Equally, if the scientists prove incompetent, the drug is quickly discovered to be unsuitable for further testing or the regulators are uncooperative, then what remains of the donation will be refunded to the donor.

Seventh, the database hosted by the Matching Agency must focus on only high-quality research. To join the list, a research group must be able to show that, although their ideas may be unusual and against current trends, the team is scientifically respected and not promoting quack medication. In our opinion, the paperwork required at this stage should be simple and quick to complete: everything must be done to avoid adding to the administrative burden that already oppresses scientists. If a donor (who must work in conjunction with a consultant) is interested in a given piece of research, and the Matching Agency agrees that the match appears promising, then the detailed assessment begins. All the relevant clinical and scientific information about the proposed trial must be gathered and reviewed by independent experts under the direction of the Medical Matching Agency: the first substantial deduction from the donor's donation will be to pay for this detailed professional study. The Matching Agency should also employ an outreach team to seek out suitable potential interventions.

The Matching Agency's function is both to collect and catalogue useful medical data and to act as a broker between donor and researcher. The Agency must therefore be composed of specialists in many areas, from data managers to medical ethicists, lawyers and scientists. As a brokerage, the Agency's job is dispassionately to facilitate and critique all aspects of the relationship between the patient investor and the scientists from the first expression of a patient's interest to the final second of the trial and subsequent publication and dissemination of the results.

The precise character and obligations of such an agency are, of course, open to discussion, but certain other elements also seem to us indispensible: it must be a not-for-profit organisation; in addition to its roles as a scientific assessor and manager of data, it will draw up a legally binding contract between the donor and the researchers to ensure that both sides stick to their original commitments, provide continuous ethical assessment of the arrangement and also take charge of all the money necessary to fund the trial from the start. This coordinating and policing body must be accountable: an appropriate higher body must oversee its behaviour. Financing the running costs of the Agency could be by way of a surcharge on the fees paid by each patient. If, as we believe, the Plutocratic Proposal represents a breakthrough in medical funding, especially for the usually overlooked rare diseases, then the start-up costs should be comparatively easy to source from statutory and charitable funders, and philanthropists with an interest in medicine and data collection/analysis.

The database hosted by the Matching Agency should be open source, free to use and publically accessible. Patients and consultants must be able to discover this database and interact with this resource easily. It is in the Agency's own interest as a reputable organisation to (1) ensure all the existing evidence about a donor's chosen neglected agent is systematically assessed to discover what is already known about this potential treatment before embarking on additional research, and (2) guarantee publication of a full report of the results of any research the Matching Agency has funded. This publication should also be freely and widely disseminated. It is not just unethical to take a vast amount of money from patients and not tell them clearly, and in a way that is readily accessible, what has been done with it; it is discourteous.

The Plutocratic Proposal is, in short, not generous. The donor must pay for everything and everyone, and expect no certitudes in return. She must be rich enough to risk losing (while still in more or less good health and with other already clinically approved treatments ahead of her) several million pounds on an experimental drug or intervention that may not yet have even been cleared for clinical trials.

\section{THE PLUTOCRATIC PROPOSAL SATISFIES THE FOUNDATIONAL PRINCIPLES OF ETHICAL RESEARCH}

The internationally accepted foundational principles of ethical research are respect for persons, beneficence and justice. We will take one popular elaboration of this list, suggested by Emanuel et $a l,{ }^{16}$ and show that not only does the Plutocratic Proposal satisfy all their stated ethical requirements for clinical studies, it also exceeds them in several respects and goes beyond the standard set by current medical funding mechanisms. 
We also believe that the Plutocratic Proposal has the potential to accelerate the drug development process and provides a model that could be adapted to other medical (ie, not just phase I and IIa clinical trials) and non-medical circumstances in which underfunding is a critical issue.

Emanuel et al expand the three broad principles of ethical research into seven points that specifically cover clinical studies:

1. Respect for enrolled subjects: 'subjects should have their privacy protected, the opportunity to withdraw and their well-being monitored.'

2. Scientific validity: 'the research must be methodologically rigorous.'

3. Favourable risk-benefit ratio: 'within the context of standard clinical practice and the research protocol, risks must be minimised, potential benefits enhanced, and the potential benefits to individuals and knowledge gained for society must outweigh the risks.'

4. Independent review: 'unaffiliated individuals must review the research and approve, amend or terminate it.'

5. Informed consent: 'individuals should be informed about the research and provide their voluntary consent.'

6. Fair subject selection: 'scientific objectives, not vulnerability or privilege, and the potential for and distribution of risks and benefits, should determine communities selected as study sites and the inclusion criteria for individual subjects.'

7. Social value: 'enhancements of health or knowledge must be derived from the research.'

The Matching Agency proposed by the Plutocratic Proposal will provide the same rigorous scientific and ethical checks that should be demanded by any reputable medical funding body. Any research proposal that threatens to exploit or dupe patients, is based on poor science or a valueless hypothesis or risks harming participants for no potential benefit will, of course, not make it past the Agency's door. Assuming that the Agency is independent, not-for-profit and properly run, the Plutocratic Proposal will satisfy as a matter of course ethical principles 1-4 in the list above.

From the researchers' point of view, the Matching Agency looks and behaves no differently to any one of a hundred other strong-minded but uncontentious funding organisations. The only oddity is that, in return for providing money for clinical research, the Agency demands the right to select one person (in the simplest version of the Plutocratic Proposal) to include on the trial, come the appropriate time. This is a right the Agency may or-if the donating patient or her sick friend or relative has since died, recovered or had a significant shift in indicationmay not be able to exercise.

The Matching Agency is, however, more than a responsible grant-giving organisation that awards and steps away. Out of due diligence to the donor-patient who has not only given the money but will also be sharing in the risks of the experiment, the Agency will oversee and facilitate the study throughout the process and subsequent publication of the results. Its responsibility to the donor-patient (and, by extension, all patients on the trial, because they make the trial possible for the donor) is far greater than for the ordinary funder that simply takes the donor's/investor's money to use as it sees fit. The job of the Agency is both to provide the funds to help the new drug to cross the 'Valley of Death' in the hope that it will reach phase II trials and to be with the lab, clinician and patient-their rod and staff-every step of the way.

There is an additional strong argument in favour of the Plutocratic Proposal based on the ethical requirement 3, that is, favourable risk-to-benefit ratio: the Matching Agency's purpose is to find neglected, high-quality, potential therapeutic agents. These are likely to be interventions for rare diseases, because these receive the least funding from other sources. The Plutocratic Proposal therefore increases, above and beyond the current systems of financing, 'the potential benefits to individuals and knowledge gained for society' by bringing new money to promising clinical research, which other funders cannot afford or have no desire to support. Rarity of disease and unprofitability of solutions are precisely the sorts of complicating factors that will bring rich patients to the Agency in order to finance clinical studies of neglected drugs.

An important ethical concern in clinical trials is, of course, how to minimise the potential for the exploitation of 'desperate' patients (although, in our experience, 'desperation' is too often used by commentators and physicians to disempower patients and ignore their noise). True desperation, rather than a justifiable and well-reasoned reassessment of priorities in the face of approaching death, could clearly affect a participants' ability to give informed consent (ethical principle 5).

Here again, the Plutocratic Proposal fares better than most traditional funding mechanisms. The independence and charitable status of the Medical Matching Agency gives it no more reason than any other properly regulated funding organisation to take advantage of the 'desperate' optimism of potential donorspatient. Although the Agency behaves towards the research team with exactly the same rigour as any traditional funding body, for the donor-patient it functions additionally as a broker. The donor has made an investment and has a powerful personal interest in ensuring that the potential for return (a good quality drug in a well-designed trial) is maximised. She does not want to invest in a dud. It is therefore central to the Agency's reputation as a trustworthy facilitator that interested donors understand the lay of the land. To avoid the Agency being sued subsequently for misrepresentation if a trial goes wrong, the donor-patient must be made fully aware of the risks she faces during a trial. She must also appreciate the low levels of success of such studies-estimated at around 13\% for a phase I cancer drug and 10\% for drugs overall ${ }^{1}$ - and understand and be able to compare with other suggested trials the limited potential for benefit.

There is a more elemental reason why the Plutocratic Proposal does not exploit desperation (whether inside or outside of quotes): desperation is not interested in such a slowpaced funding mechanism. The donor-patient must, in general, expect it to take at least 3 years to bring neglected potential treatments into clinical trials. This is deeply unattractive to a desperate person, who wants something yesterday. There is a much greater chance that a consultant offering a dying patient one last shot at health by suggesting she enrol on a new trial starting next week will, despite all best efforts to the contrary, be playing on the patient's desperation; yet this is a daily occurrence in hospitals around the world.

Another understandable protest against a scheme in which patients pay for participation is that the participants will be able to fund only early phase trials-later phases are simply too expensive-and these are the least likely to be effective, thereby providing further pressure to exploit patient 'desperation'. ${ }^{17}$

For committed philanthropy schemes such as the Plutocratic Proposal, which do not exploit desperation, this is not an ethical point but a practical one. The Proposal in its simplest form is limited to funding early phase trials because such studies do not involve comparison wings, and it is unlikely that any donor-patient will want to support a trial in which there is a $50 \%$ chance she will not receive the drug she paid for. 
Barring exceptions such as phase IIb crossover studies which might yet appeal to a donor-patient, this leaves the Plutocratic Proposal (at least, in our simplest formulation) to fund only phase I and IIa trials. Comparison is fundamental as a basis for causal inferences about the effects of an intervention, but the job of the Plutocratic Proposal is limited to helping neglected candidate drugs to reach that stage of research, not guiding them through it. Either a patient will accept that a phase I study is extremely unlikely to have any therapeutic effect (but is, for example, nevertheless worth considering because it might lead to a phase IIa study where efficacy is slightly more likely) or she will not. If she does not accept this dispiriting state of affairs, she does not lay down her money. Even so, we believe the Proposal will be an attractive proposition to many donorpatients. There are roughly one and a quarter million people in the world worth more than $\$ 5$ million. ${ }^{18}$ Take our chosen example of neuroendocrine cancer, for which (in its various forms) the incidence is between five and six people per 100000 per year ${ }^{19}$ : this suggests that, every year, at least 70 new extremely wealthy patients and their relatives could be expected to take a serious interest in the Plutocratic Proposal's method of funding fresh research. Of course, if more than one patientdonor is allowed per trial, the amount each needs to contribute decreases, and the chance of finding potential donors increases markedly.

Vince Hamilton, the donor in the Uppsala trial, gave $£ 1.5$ million for the chance to take part in a phase I/IIa trial. When one of us (AM) flew out to meet him in Geneva, Mr Hamilton also wanted to pay fully for nine other phase I or phase II studies, on the chance that one or two of these might be suitable for his disease as well. As an oilman, he understood the high risk of clinical failure by analogy: he compared it to the failure rate of drilling an unsuccessful oil well, about 90\%. He wondered why all very rich people with diseases did not fund medical trials under these terms. As a further illustration of how the Plutocratic Proposal can improve informed consent (ethical principle 5) by giving the donor-patient a greater sense of connection and investment in the trials process (while also bringing in any useful fiscal and business expertise such patients might have), Mr Hamilton then flew to Baylor to negotiate a $25 \%$ reduction in the cost of production of the Uppsala drug.

Efficacy becomes an issue in phase IIa, and there are many additional neglected potential therapeutic agents that can re-enter the trials process at this point. Repositioned and repurposed drugs will, unless the indication is significantly different, have already passed safety tests; two of the three other neglected interventions we studied during our fundraising for Uppsala, discussed earlier, were also ready for phase II studies in certain indications. In the case of SVV, the drug was in phase II for small cell lung cancer and stalled half way through a phase I study for paediatric brain cancers. In the Manchester case, the tolerable and toxic doses of the chemotherapeutic drugs to be used are well understood. What was being suggested was a form of repositioning.

The rich crop of drugs potentially suitable for repurposing or repositioning is naturally very attractive to the Plutocratic Proposal; it also introduces another exciting possibility. So far, we have talked about the Plutocratic Proposal only as a means to rescue neglected interventions. Couldn't it also fund research into new compounds? Let us say our donor-patient discovers certain biomarkers are particular to her illness. Couldn't she ask the Matching Agency to approach a genomics group, to see if researchers could design a bespoke drug that would target her indication? In our initial discussions with one such group, the scientists have suggested that in many cases a new compound could be designed and ready for clinical trials in 3 years.

A scheme in which all patients pay to participate in a clinical study will not, by its nature, allow fair patient selection (ethical principle 6): although the disease may affect rich and poor alike, only the rich are being allowed on the trial and that is unfair.

This is not true of a committed philanthropy mechanism such as the Plutocratic Proposal. Here only one rich person is necessary to make a previously neglected trial go ahead; all other participants are selected as they would be for any other ethically approved clinical research. Because of one very rich patient's donation, poorer patients have access to a potential therapeutic agent that would previously not have been available to them. What the donor is saying is, in effect, "I will pay all the costs of setting up and running the trial for all the other participants. All I ask is that, in return, assuming I am also still a suitable candidate, I also get to share the benefits and risks of taking part." The donor-patient is 'guaranteed' (a generally unfair word in trial terms) participation in the forthcoming trial if and only if she meets the inclusion criteria once the testing begins.

Nevertheless, this is, ethically, a possible weak spot of the Plutocratic Proposal for some. A phase I trial may have as few as 10 patients. Even one unguaranteed but reserved place is a notable percentage of the total. On the one hand, an intervention that would not otherwise be tested is being brought into clinical trials; on the other hand, on top of all those financial privileges she already possesses, the rich patient who is paying for the new study is being given still one more privilege on top, that is, the preferential right to participate in the study.

One possible response is to make the donor a supernumerary participant. This would be trial +1 . She still must pay for it all, but now the research will remain statistically useful whether or not the donor, or anybody else, takes up her putative place. But is this the start of a slippery slope to an unfair expanded access programme? What is to stop a second plutocratic patient buying her way into participation, so that it becomes trial +2 ? And if she does, does it matter? There are still 10 ordinary patients getting access to something that would not otherwise be within their reach. How far can the point be stretched? If we agree with Savulescu that up to half the patients should be allowed to pay for a place, is there any significant ethical difference between the donors being supernumerary patients (ie, up to 10 more rich people being invited to participate) or half of the original trial cohort (ie, up to 5 of the 10 trial participants)?

There is another aspect to remember here. It is often difficult to recruit sufficient numbers of patients to trials, especially for studies investigating rare diseases. ${ }^{20}$ In such cases, the donor's participation will also help to ensure the trial's social value (ethical principle 7) by increasing the chance that the trial can be completed and the results published.

Social value is an area in which the Plutocratic Proposal also goes further than other currently accepted schemes. The Proposal is a funding mechanism that will encourage neglected, high quality, high-quality research using new money. For its own reputation and legal protection the Matching Agency must do a systematic review of all known existing research and, in order to ease this process, must itself be committed to publishing full research results. These are definitively ethical matters: failure to do one or both has, in the past, had fatal consequences for patients and research participants. Yet many respected funders do neither. Emanuel et al do not even mention these two vital points concerning publication in their 
original list of seven ethical requirements, or in any of its subsequent variations.

\section{CONCLUSION}

The Plutocratic Proposal is a new type of funding mechanism that is especially suited to helping neglected interventions for orphan diseases progress through the early stages of clinical development. We believe it is a system that, in its own interest, would promote ethical trials, according to the seven requirements set out by Emanuel et al. ${ }^{17}$

We have mentioned several times that the Plutocratic Proposal discussed here is the simplest variant of the idea. It is easy to imagine a version in which two or more patients pay for the trial in return for two or more places, or one that funds not just neglected but de novo work. An elegant adjustment, suggested by Peter Lanciano, the former CEO of Neotropix (the company that put SVV into clinical trials), attempts to include off-label usage, should the indication of the donor change. ${ }^{1}$ We are currently considering a 'corporate' modification that we believe is more suited to neglected research into neglected infectious diseases (rather than neglected drugs). Each of these alternatives brings in new ethical questions and emphases.

Finally, we should note that the phase I clinical trial of AdVince that we funded (together with 2000 other patients and activists from around the world) began last April. Neither Dido Davies, the friend who inspired our 4 years of campaign work, nor Vince Hamilton, who helped us to succeed, lived to see the day. The first recipient of the new drug was Jan-Erik Jansson, a fire fighter from Norrtälje, a coastal town about an hour's drive from the hospital in Uppsala. "This private person, they offer a lot", he said when being filmed for the iCancer website, "for they offer me a chance". ${ }^{21}$

Twitter Follow Dominic Nutt @DominicNutt

Acknowledgements The authors are grateful to the following for their advice and assistance in the development of the idea of the Plutocratic Proposal, and their comments about this paper, which have greatly improved it: Chas Bountra, David Carter, lain Chalmers, Flora Dennis, Magnus Essand, Mona Hamilton, Peter Lanciano, Wenhwa Lee, Justyna Leja-Jarblad, Craig Lipset, Piers Mahon, Dan O'Connor, Julian Savulescu, Liz Scarff and Effy Vayena

Funding VictoryNET.

Competing interests This paper was conceived and proposed by AM and DN who obtained a grant from VictoryNET, a trust set up by Vince Hamilton to fund research into and promote understanding of neuroendocrine cancer. The grant covered the costs (travel, research, time) while the authors worked on the paper. VictoryNET is not responsible for the content of the paper and has not sought to influence it.

Patient consent Obtained

Provenance and peer review Not commissioned; externally peer reviewed.

Open Access This is an Open Access article distributed in accordance with the Creative Commons Attribution Non Commercial (CC BY-NC 4.0) license, which permits others to distribute, remix, adapt, build upon this work non-commercially, and license their derivative works on different terms, provided the original work is properly cited and the use is non-commercial. See: http://creativecommons.org/ licenses/by-nc/4.0/

\section{REFERENCES}

1 Hay M, Thomas DW, Craighead JL, et al. Clinical development success rates for investigational drugs. Nat Biotechnol 2014;32:40-51.

2 Tufts Centre for the Study of Drug Development. Clinical Study Failures Vary Widely by Phase of Study and Therapeutic Class. 10 September 2013. http://csdd.tufts.edu/ news/complete_story/pr_ir_sep_oct_2013 (accessed Mar 2017). The Centre investigated the development histories of 812 compounds and established reasons for failure by clinical phase of 410 .

3 Adams DJ. The Valley of Death in anticancer drug development: a re-assessment. Trends Pharmacol Sci 2012:33:173-80.

4 Butler D. Translational research: crossing the valley of death Nature 2008:453:840-2.

5 Eastmann Q. DRIVE through the 'Valley of Death', Emory Medicine, 2014, Winter 2013/14.

6 Masters A. A Plutocratic Proposal. Mosaic 27 October, 2014. http://mosaicscience. com/story/plutocratic-proposal (accessed Mar 2017).

7 Nosengo N. Can you teach old drugs new tricks? Nature 2016;534:314-16.

8 Institute of Cancer Research, Cancer drug discovery system is broken, global summit hears, 24 October 2014. http://www.icr.ac.uk/news-archive/ cancer-drug-discovery-system-is-broken-global-summit-hears (accessed Mar 2017).

9 Nutt D. Would I take an untested treatment cancer treatment myself? Hell yes!, The Telegraph, 14 September 2012. http://www.telegraph.co.uk/news/health/9544400/ Would-I-takean-untested-cancer-treatment-myself-Hellyes.html

10 The Carcinoid Foundation, Oncolytic virus clinical trial for neuroendocrine tumour patients begins at Uppsala University Sweden, 6 April 2016. http://www.carcinoid org/2016/04/06/oncolytic-virus-clinical-trial-neuroendocrine-tumor-patients-beginsuppsala-university-sweden/ (accessed Mar 2017).

11 Leja J, Dzojic H, Gustafson E, et al. A novel chromogranin-A promoter-driven oncolytic adenovirus for midgut carcinoid therapy. Clin Cancer Res 2007;13:2455-62.

12 Leja J, Nilsson B, Yu D, et al. Double-detargeted oncolytic adenovirus shows replication arrest in liver cells and retains neuroendocrine cell killing ability. PLoS ONE 2010;5:e8916

13 Yu D, Jin C, Leja J, et al. Adenovirus with hexon Tat-protein transduction domain modification exhibits increased therapeutic effect in experimental neuroblastoma and neuroendocrine tumors. J Virol 2011;85:13114-23.

14 Leja J, Yu D, Nilsson B, et al. Oncolytic adenovirus modified with somatostatin motifs for selective infection of neuroendocrine tumor cells. Gene Ther 2011;18:1052-62.

15 Anaand G. Saying No to Penelope, Wall Street Journal, 1 May, 2007. http://www wsj.com/articles/SB117798196751887629

16 Emanuel EJ, Wendler D, Grady C. What makes clinical research ethical? JAMA 2000;283:2701-11.

17 Emanuel EJ, Joffe S, Grady C, et al. Clinical research, should patients pay to play? Sci Transl Med 2015;7:298-314.

18 Consultancy.uk. Global HNWI wealth hits $\$ 60$ trillion among 15.4 million people. 4 July 2016. http://www.consultancy.uk/news/12254/global-hnwi-wealth-hits-60trillion-among-154-million-people (accessed Mar 2017).

19 Hallet J, Law CHL, Cukier M, et al. Exploring the rising incidence of neuroendocrine tumors: a population-based analysis of epidemiology, metastatic presentation, and outcomes. Cancer 2015;121:589-97.

20 DeWard SJ, Wilson A, Bausell $\mathrm{H}$, et al. Practical aspects of recruitment and retention in clinical trials of rare genetic diseases: the phenylketonuria (PKU) experience. J Genet Couns 2014;23:20-8.

21 Short film on http://www.iCancer.org.uk. Jan-Erik at 00:01:36. April 2016 (accessed Mar 2017). 